\title{
Hizmetkar Liderliğin Örgütsel Bağlılık Üzerindeki Etkisinde Psikolojik Güçlendirmenin Aracılık Rolü
}

\author{
Mustafa NAL \\ Afyon Kocatepe Üniversitesi Dinar Uygulamalı Bilimler Yüksekokulu \\ mustafanal@aku.edu.tr \\ ORCID ID: 0000-0002-3282-1124 \\ Gülfer BEKTAŞ \\ Acıbadem Üniversitesi Sağlık Bilimleri Fakültesi \\ gulfer.bektas@acibadem.edu.tr \\ ORCID ID: 0000-0002-0110-4181 \\ Ender KAYA \\ Özel Pendik Bölge Hastanesi \\ kayaender@hotmail.com \\ ORCID ID: 0000-0003-0361-5177
}

\begin{tabular}{lrr} 
Araştırma Makalesi & DOI: $10.31592 /$ aeusbed.736060 \\
\hline Geliş Tarihi: 15.05 .2020 & Revize Tarihi: 21.09 .2020 & Kabul Tarihi: 12.11 .2020
\end{tabular}

\section{Atıf Bilgisi}

Nal, M., Bektaş, G. ve Kaya, E. (2020). Hizmetkar liderliğin örgütsel bağlılık üzerindeki etkisinde psikolojik güçlendirmenin aracılık rolü. Ahi Evran Üniversitesi Sosyal Bilimler Enstitüsü Dergisi, 6(3), 842-858.

\section{ÖZ}

$\mathrm{Bu}$ araştırma hizmetkar liderliğin örgütsel bağllık üzerindeki etkisinde psikolojik güçlendirmenin aracılık rolünü incelemek amacı ile yapılmıştır. Araştırmanın örneklemini İstanbul ilinde faaliyet gösteren özel bir hastanede görev yapan 222 sağlık çalışanı oluşturmaktadır. Araştırmada veri toplama aracı olarak anket kullanılmıştır. Verilerin analizinde IBM SPSS 25.0 programı kullanılmıştır. Değişkenler arasındaki ilişkinin incelenmesinde Pearson Korelasyon Analizi ve Basit Doğrusal Regresyon Analizi kullanılmıştır. Aracılık testinin analizinde Process Makro v3.4 uygulaması ile IBM SPSS programı kullanılmıştır. Katılımcıların hizmetkar liderlik algısı puan ortalaması $3.70 \pm 0.87$, örgütsel bağlılık puan ortalaması $3.04 \pm 0.54$, psikolojik güçlendirme puan ortalaması $3.95 \pm 0.65$ olarak tespit edilmiştir. Yapılan analiz sonucunda hizmetkar liderliğin psikolojik güçlendirme ve örgütsel bağl1lık üzerine pozitif etkisi olduğu tespit edilmiştir. Ayrıca, regresyon analizi sonucuna göre psikolojik güçlendirmenin örgütsel bağlıllk üzerinde pozitif yönde ve anlamlı bir etkisi olduğu belirlenmiştir. Ancak hizmetkar liderliğin örgütsel bağl1lık üzerindeki etkisinde psikolojik güçlendirmenin aracılık etkisinin olmadığı saptanmıştır. Türkiye'de hizmetkar liderliğin örgütsel bağl1lık üzerindeki etkisinde psikolojik güçlendirmenin aracılık etkisini araştıran başka bir çalışamaya rastlanmamıştır. $\mathrm{Bu}$ nedenle bu konuda sağlık sektöründe yeni araştırmaların yapılması uygun olacağı düşünülmektedir.

Anahtar Kelimeler: Hizmetkar liderlik, örgütsel bağlılık, psikolojik güçlendirme.

\section{The Intermediary Role of Psychological Empowerment in the Effect of Servant Leadership on Organizational Commitment}

\begin{abstract}
This research was conducted to examine the intermediary role of psychological empowerment on the impact of servant leadership on organizational commitment. The sample of the study consists of 222 healthcare professionals working in a private hospital in Istanbul. In the research a questionnaire was used as the main data collection tool. IBM SPSS 25.0 program was used to analyze the data. Pearson Correlation Analysis and Simple Linear Regression Analysis were used to examine the relationship between variables. In the analysis of the moderator effect, the Process Macro v3.4 application and IBM SPSS program were used. Participants' perception of servant leadership score was determined as $3.70 \pm 0.87$, average of organizational commitment score was $3.04 \pm 0.54$, and psychological empowerment score average was $3.95 \pm 0.65$. The analysis demonstrated that servant leadership has a positive effect on psychological empowerment and organizational commitment. Also, according to the regression analysis result, psychological empowerment has a positive and significant effect on organizational commitment. However, it was observed that psychological empowerment does not play intermediary role on the impact of servant leadership on organizational commitment. There is no other research examining the intermediary role of psychological empowerment in the impact of servant leadership on organizational commitment in Turkey. Therefore, it is considered that it will be appropriate to conduct new researches in the health sector on this subject.
\end{abstract}

Keywords: Servant leadership, organizational commitment, psychological empowerment. 


\section{Giriş}

Liderlik davranışları ile ilgili araştırmalar 1900'lü yılların başlarından beri devam etmektedir. $\mathrm{Bu}$ araştırmalar sonucunda liderlerin göstermiş olduğu davranışlara göre birçok liderlik türü (karizmatik, dönüşümcü, işlemsel, paternalist vb.) tanımlanmıştır. Greenleaf 1970), ise "hizmetkar liderlik" adı altında yeni bir liderlik tarzını ileri sürmüştür. Ancak araştırmacıların hizmetkar liderlik üzerine ilgisi 1990 itibari ile oluşmuş ve bu dönemde hizmetkar liderlik ile ilgili araştırmaların sayısının arttığı görülmüştür. Günümüzde de hizmetkar liderlik ile ilgili çalışmalar giderek artmaktadır. Genel olarak bu araştırmaların asıl konusu yöneticilerin hizmetkar liderlik kapsamındaki davranışlarının, çalışanların davranış ve tutumlarını ne şekilde etkilediğini saptamaya yönelik olmuştur. Yapılan araştırmalarda hizmetkar liderlik ile örgütsel bağlılık (Cerit, 2010; Harwiki, 2016; Lapointe ve Vandenberghe, 2018; Miao, Newman, Schwarz ve Xu, 2014; Ramli ve Desa, 2014), psikolojik güçlendirme (Bolat, Bolat ve Yüksel, 2016; Zorlu, Avan ve Baytok, 2019), örgütsel adalet, örgütsel özdeşleşme (Ateş, 2015), iş doyumu (Tanrı̈̈̆gn ve Çoban, 2019,), lider-üye etkileşimi (Dal, 2014), örgütsel vatandaşlık (Baytok ve Ergen, 2013) ilişkileri incelenmiştir. Bu çalışmada ise hizmetkar liderliğin örgütsel bağlılık üzerindeki etkisinde psikolojik güçlendirmenin aracılık rolü incelenmiştir.

Örgütsel bağl1lığın, çalışanların iş doyumu (Erdağı, 2018), örgütsel vatandaşlık davranış1 (Çelik ve Üstüner, 2020), motivasyon (Özata ve Topçu, 2018), performans (Kılınç ve Yener, 2019) tutum ve davranışlarını olumlu yönde etkilemekte iken, iş stresi, (Turhan Demirkol ve Özdemir, 2018), işten ayrılma niyeti (Erdoğdu ve Sökmen, 2019), örgütsel sinizm (Yorulmaz ve Çelik, 2016), gibi tutum ve davranışları ise azaltıcı etkisi vardır.

Psikolojik güçlendirmenin, çalı̧̧anların iş performansı (Kanbur, 2018), motivasyon (İhtiyaroğlu, 2017), iş doyumu (Karakuş, 2019), örgütsel vatandaşlık davranış1 (Çavuşoğlu ve Güler, 2017), örgütsel bağl1lık (Aji, Hamid, Hassan ve Rasdi, 2017; Joo ve Shim, 2010; Odabaş, 2014) gibi davranış ve tutumları arttırıcı etkisi var iken, işten ayrılma niyeti (Kanbur, 2018), tükenmişlik (Kaya ve Altınkurt, 2018), örgütsel sinizm (Torun, 2016) gibi örgüt açısından olumsuz olarak nitelendirilebilecek tutum ve davranışlar üzerinde ise azaltıcı etkisi vardır.

$\mathrm{Bu}$ araştırmada ilk olarak hizmetkar liderliğin örgütsel bağlllık ve psikolojik güçlendirme üzerine etkisi analiz edilecek, daha sonra ise hizmetkar liderliğin örgütsel bağlılık üzerindeki etkisinde psikolojik güçlendirmenin aracılık rolü test edilecektir. Yapılan literatür araştırmasında bu konuda yapılan çok fazla çalışma olmadığı görülmüş hatta bu konuda Türkiye'de yapılan bir araştırmaya rastlanmamıştır. Yapılan bu araştırmanın literatürdeki bu boşluğu doldurmaya yönelik katkı sağlaması amaçlanmıştır.

\section{Hizmetkar Liderlik}

"Liderlik, hedef belirleme ve hedefe ulaşma yönündeki organize bir grubun faaliyetlerini etkileme süreci olarak tanımlanabilir" (Stogdill, 1950, s. 4). "Lider, başkalarını belirli amaçlar doğrultusunda davranış göstermeye sevk eden etkileyen kişidir. Bir diğer deyişle lider, bir grup insanın, kendi bireysel ve grup amaçlarını gerçekleştirmek için takip ettikleri, onun istek, emir ve talimatları doğrultusunda hareket ettikleri kişiye denir" (Koçel, 2011, s. 569). "Liderlik, insanları örgütsel, siyasi, psikolojik ve diğer kaynakların paylaşımında rekabet söz konusu olduğunda veya çıkar çatışması olduğunda, belirli amaç doğrultusunda onları motive etmek, harekete geçirmek ve tatmin etmek için kullanılmaktadır" (Burns, 1979, s. 381). Liderler, birlikte çalıştığ 1 ve yönettiği kişilere ilham verebilen ve onların iş yaşamlarında olumlu etkisi olan niteliklere sahiptirler (Biçer, 2020).

Liderlik ile ilgili çalışmalar 20. yüzyılın başlarında başlamış ve günümüzde halen devam etmektedir. Yapılan çalışmalar neticesinde, karizmatik liderlik, otoriter liderlik, demokratik liderlik, tam serbesti tanıyan liderlik, dönüşümcü liderlik, etkileşimci liderlik, paternalist liderlik vb. birçok liderlik türü tanımlanmıştır. Son yıllarda üzerinde araştırmaların yoğunlaştığı liderlik türlerinden biri 
de hizmetkar liderliktir. Hizmetkar liderlik kavramı ilk olarak Robert Greenleaf (1970), tarafindan kullanılmıştır. Greenleaf (1970, s. 6), "hizmetkar liderin davranışlarının öncelikle kişinin doğal hisleri ile başladığını ve bilinçli olarak bu hislerini devam ettirerek hizmetkâr liderlik şeklini aldığını" ifade etmektedir. Daha sonra Greenleaf (2002, s. 27), "hizmetkar lideri, bir kılavuz olmaktan öte, hizmet etmeye istekli olan biri" olarak tanımlamıştır. Page ve Wong (2000, s. 2), "hizmetkar liderliği, çalışanlar ile ortak amaç ve hedeflere ulaşmak için onların refahı ve gelişimlerine katkı sağlamak için çalışan onlara hizmet eden lider" olarak tanımlamıştır. Barbuto ve Wheeler (2006, ss. 304-305), "hizmetkar liderliği, hizmet etme arzusu ve kişisel çıkarlarını başkalarının çıkarlarına feda etmeye istekli olma" şeklinde tanımlamışlardır.

"Hizmetkar liderler, organizasyonun amaçlarından daha çok takipçilerine odaklanmaktadır ve organizasyon çıkarları için en iyi davranış liderin takipçilerine güvenmesidir" (Stone, Russell ve Patterson, 2004, s. 355). Takipçiler hizmetkar liderlik davranışına maruz kaldığı zaman hizmetkar liderlik kültürü gelişmiş olur. Takipçiler, örgütsel vatandaşlık davranışı gibi liderlerine ve diğer takipçilerine fayda sağlayan davranışlarda bulunarak liderin vermiş olduğu desteğe karşıllı verirler (Ehrhart, 2004). Hizmetkar lider, bir ortaklık ve ekip çalışmasına dayanan, karar alma sürecine takipçilerini de dahil etmeye çalışan, ahlaki ve yardımsever davranışlara dayanan ve örgütün kalite ve gelişimini artırırken çalışanların kişisel gelişimini de artırmaya çalışan lider olarak tanımlanabilir. Hizmetkar liderin özelliklerinden biri de kararları paydaşları ile birlikte almasıdır (Spears, 2010, s. $11)$.

Spears (2004, s. 11), ise hizmetkar liderin özelliklerini; "aktif dinleyici, empati yapabilen, zor konuları kavrayan, ikna yeteneği olan, ileri görüşlü, farkındalığı yüksek, hizmetkar davranışlar gösteren, iyileştirici, çalışanların gelişimine odaklanan ve ekip kurma yeteneğine sahip kişi” olarak sınıflandırmıştır.

Barbuto ve Wheeler (2006, ss. 304-309), hizmetkar liderliğin özelliklerini; "fedakarlık çağrısı, duygusal destek, bilgelik, ikna edicilik, örgütsel yöneticilik şeklinde tanımlamışlardır. Fedakarlık çağrısı, liderin başkalarının yaşamlarında olumlu bir fark yaratma konusundaki köklü arzusudur. Nihai hedef hizmet etmek olduğundan, bu özelliklere sahip liderler başkalarının çıkarlarını kendi çıkarlarının önüne geçirerek ve titizlikle takipçilerin ihtiyaçlarını karşılamak için çalışmaktadır. Duygusal destek, liderin sıkıntı veya travmadan manevi iyileşmeyi teşvik etme taahhüdünü ve becerisini tanımlar. Duygusal desteği kullanan liderler son derece empatik ve mükemmel dinleyicilerdir. Çalışanların kişisel ve mesleki sorunlarını dile getirmeleri için güvenli ortamlar oluştururlar. Bilgelik, çevrenin farkında olmanın ve sonuçların beklentisinin bir kombinasyonudur. $\mathrm{Bu}$ niteliğe sahip liderler, çevreden ipuçlarını almak ve sonuçlarını anlamak konusunda beceriklidir. İkna edicilik, bir liderin sağlam akıl yürütmeyi ve zihinsel çerçeveleri ne ölçüde kullandığıdır. Bu özellikte yüksek puan alan liderler ikna edicidir ve başkalarının bir şeyler yapmasını sağlamak için zorlayıcı nedenler sunar. Örgütsel yöneticilik, liderlerin bir toplumu, toplumsal gelişimi, programları ve sosyal yardım yoluyla topluma olumlu bir katkıda bulunmaya hazırlama derecesini tanımlar. Bu liderler ayrıca işyerinde olumlu bir miras bırakmaya hazırlanan bir topluluk ruhu geliştirmek için çalışmaktadırlar”.

Hamilton (2008), hizmetkar liderin örgüte olumlu katkılarının olabileceğini ifade etmektedir. $\mathrm{Bu}$ katkılar; "görev ve değer odaklılık, yaratıcılık ve yenilikçilik, sorumluluk ve esneklik, içsel ve dışsal işe bağlılık, çalışanlara saygılı olma, çalışan sadakati ve örgüt içindeki farklılıkları hoş görme" şeklinde olduğunu belirtmiştir (Melchar ve Bosco, 2010, ss. 77-78).

\section{Örgütsel Bağlılık}

Literatürde örgütsel bağl1lık kavramını ilk kullanan kişi Whyte (1956), olmuştur. "Whyte'a (1956), göre örgüt ile çalışan arasında görünmeyen bir sözleşme vardır ve çalışanın örgütüne bağlı olduğu oranda, örgütte çalışanına bağlıdır” (Tufail, Zia, Khan, ve Irfan, 2012, s. 83).

Buchanan (1974, s. 533), "örgütsel bağl11ı̆̆ı, çalışılanların örgütten karşılık beklemeden, örgüt değerleri ve amaçları ile bütünleşerek içinde bulunduğu örgüte karşı sorumluluk duyması" olarak 
tanımlamaktadır. Mowday (1979, s. 226), "örgütsel bağlılığı, kişinin işine ve iş yerine olan ilgisini güçlendirerek, örgüte bağlı davranışlar göstermesi, örgüt ve çalışanın uyum içinde olması", şeklinde ifade etmektedir. Wiener (1982, s. 418), "örgütsel bağl1lı̆̆1, örgütsel çıkarları gerçekleştirmeye yönelik davranışları göstermek için var olan içselleştirilmiş normatif baskıların toplamı”, olduğunu savunmuştur. Reichers (1985, s. 465), ise "örgütsel bağl1lı̆̆1, bir örgütün amaçları yönünde, üst yönetim, müşteriler, sendikalar ve toplumun çoğunluğu gibi birçok faktör ile özdeşleşme süreci", olarak açıklamıştır. Eren (2015, s. 555), "örgütsel bağlılı̆̆ 1 , kişinin bireysel istek, amaç ve değerlerine katkıda bulunan, onların gerçekleşmesine olanak sağlayan, örgütün amaçlarına bağlılık hatta sadakatle hizmet etme, örgüt lehine özverili davranma, kendini örgüte adama, duygu ve tutumları", olarak tanımlamıştır. Meyer ve Allen (1991), örgütsel bağl11ı̆̆ 1 ; normatif bağlılık, devamlılık bağl1lığı ve duygusal bağl1lık olarak üç boyutta ele almışlardır. "Normatif bağl1lık, çalışanın örgütte kalmayı ahlaki açıdan doğru olduğu inancına bağlı olarak oluşan bağlılık duygusunu", "devamlılık bağlılığ1, örgütten ayrılmanın kişiye yükleyeceği yüksek maliyetlerden dolayı kişiyi örgütte kalmaya zorlayan duyguyu" duygusal bağlılık, çalışanın duygusal anlamda kendi tercihi ile örgütte kalma isteğini” ifade etmektedir (Meyer ve Allen, 1997, s. 11). Özdemir (2019, s.238), ise örgütsel bağlıllğı, "bireylerin maaş karşıllı̆ı çalıştıkları örgütlerine karşı bağl1lıkları ve çalıştığı örgütün başarılı olabilmesi için gösterdiği çabaların toplamı” olarak tanımlamaktadır.

"Örgütsel bağl1lıktan söz etmek için kişinin örgütü yürekten benimsemesi, onun amaçlarını, kurallarını, norm ve kültürünü kabul etmesi, saygı göstermesi ve onu destekleyici davranışta bulunması gerekmektedir" (Eren, 2015, s. 555). Meyer ve Allen'a (1997, s. 3) göre ise "örgütsel bağl1lığa sahip kişiler; her koşulda örgütte kalan, işine düzenli olarak devam eden, tam bir iş gününü hatta daha fazlasını örgütsel amaçlar için harcayan, örgütün varlıklarını daima koruyan ve örgütsel amaç ve vizyonunu paylaşan kişilerdir". "Örgütsel bağlılığın düşük olduğu durumlarda, işten ayrılma, devamsızlık ve geç gelme, performansta düşme, iş stresinde artma" (Duygulu ve Abaan, 2007, s. 65), "başarısızlık korkusu, kalıcı oyalanma ve kalıcı başarı eksikliği durumları ile karşılaşılabilmektedir" (Lowman, 1993, s. 52).

\section{Psikolojik Güçlendirme}

"Yönetim kavramı olarak güçlendirme, yardımlaşma, paylaşma, yetiştirme ve ekip çalışması yolu ile çalı̧̧anların karar vermelerini, inisiyatif kullanabilmelerini ve sorumluluk alabilmelerini sağlayarak çalışanları işin sahibi haline getirmeyi amaçlamaktadır" (Koçel, 2011, s. 408-409). Conger ve Kanungo (1988, s. 474), güçlendirmeyi "güçsüzlüğü teşvik eden koşulların tanımlanması ve bunların hem resmi örgütsel uygulamalar hem de etkinlik bilgisi sağlama amaçlı gayri resmi tekniklerle ortadan kaldırılması yoluyla örgüt üyeleri arasında öz-yeterlik duygularını geliştirme süreci” olarak tanımlamaktadır.

“Thomas ve Velthouse, (1990), güçlendirmenin çok yönlü olduğunu ve özünün tek bir kavramla açıklanamayacağını savunmuştur. Güçlendirmeyi daha geniş olarak, bireyin iş rolüne yönelimini yansıtan dört biliş (etki, yetkinlik, anlamlılık ve seçim) ile ortaya çıkan artan içsel görev motivasyonu olarak tanımlamışlardır. Anlamlılık, bireyin kendi ideallerine veya standartlarına göre değerlendirilen görev hedefinin veya amacının değeri ile ilgili durumdur. Başka bir deyişle, bireyin belirli bir görev hakkındaki içsel sempatisini ifade eder. Seçim, bireyin eylemleri başlatma ve düzenleme konusunda tercih yapma duygusudur. Yetkinlik, bireyin görev faaliyetlerini ustalıkla yapabilme derecesini ifade etmektedir. Etki, görevin amacını gerçekleştirme, yani kişinin görev ortamında amaçlanan etkiler üretme açısından davranışın "fark yaratma" derecesini ifade eder" (Thomas ve Velthouse, 1990, ss. 672-673).

Spreitzer'e (1995), göre bu boyutlardan birinin eksikliği, algllanan güçlülük duygusunu tamamen ortadan kaldırmasa da düzeyini azaltmaktadır. "Psikolojik güçlendirme, bireylerin işi ile ilgili kontrol duygusu için gerekli olan bir tür psikolojik durumdur. Psikolojik bakış açısı, tüm düzeylerde çalışanlarla yetkiyi paylaşarak, yönetimsel uygulamalar yerine, çalışanların işlerini nasıl yaptığına odaklanmaktadır ve güçlendirmenin, çalışanların rollerine ilişkin sahip oldukları kişisel inançlar" olarak açıklamaktadır (Spreitzer, 2007, s. 6). 
“Güçlendirme süreçleri, örgütsel değişiklikler karşısında örgüt üyelerinin moral bozukluğunu azaltmada veya örgüt üyelerini zor rekabet koşulları karşısında harekete geçirme konusunda liderlere kolaylık sağlayabilir. $\mathrm{Bu}$ süreçler liderlerin daha yüksek performans hedefleri belirlemelerine olanak sağlayabilir ve çalışanların bu hedefleri kabul etmelerine yardımcı olabilir. Güçlendirme uygulamaları, zor organizasyonel ya da çevresel engellere rağmen astların çalışmalarına devam etmeleri için motive edilmesinde de yararlı olabilir” (Conger ve Kanungo, 1988, s. 476).

Psikolojik güçlendirme ile ilgili yapılan tanımlar ve değerlendirmeler incelendiğinde psikolojik güçlendirmenin hem çalışan hem lider hemde örgüt açısından olumlu katkıları olduğu söylenebilir.

\section{Araştırmanın Alt Problemleri}

$\mathrm{Bu}$ araştırma kapsamında yedi adet alt problem (AP) belirlenmiştir.

AP1. Hizmetkar liderlik ile örgütsel bağl1lık arasında istatistiksel açıdan anlamlı pozitif bir ilişki var mıdır?

AP2. Hizmetkar liderliğin örgütsel bağl1lık üzerine pozitif etkisi var mıdır?

Hizmetkâr liderlik ile örgütsel bağl1lık arasındaki ilişkinin incelendiği araştırmalarda (Cerit, 2010; Harwiki, 2016; Lapointe ve Vandenberghe, 2018; Miao, vd., 2014; Ramli ve Desa, 2014), hizmetkar liderlik ile örgütsel bağlllık arasında pozitif ilişki olduğu tespit edilmiștir. Liderlerin davranışlarının çalışanların örgütsel tutum ve davranışları üzerine etkilerileri olduğu bilinmektedir. $\mathrm{Bu}$ çalışmada da hizmetkar liderlik ile örgütsel bağl1lık arasında pozitif ilişki olabileceği düşünülmektedir.

AP3. Hizmetkar liderlik ile psikolojik güçlendirme arasında istatistiksel açıdan anlamlı pozitif bir ilişki var mıdır?

AP4. Hizmetkar liderliğin psikolojik güçlendirme üzerine pozitif etkisi var mıdır?

Hizmetkar liderlik ile psikolojik güçlendirme arasındaki ilişkinin incelendiği araştırmalarda (Bolat, vd., 2016; Zorlu, vd., 2019), hizmetkar liderlik ile psikolojik güçlendirme arasında pozitif ilişki olduğunu saptamışlardır. Daha önceki çalışmaların da olduğu gibi bu çalışmada da hizmetkar liderliğin psikolojik güçlendirme üzerine pozitif etkisi olabilceği düşünülmüştür.

AP5. Psikolojik güçlendirme ile örgütsel bağl1lık arasında istatistiksel açıdan anlamlı pozitif bir ilişki var mıdır?

AP6. Psikolojik güçlendirmenin örgütsel bağlılık üzerine pozitif etkisi var mıdır?

Psikolojik güçlendirme ile örgütsel bağl1lık arasındaki ilişkiyi tespit etmek için yapılan araştırmaların (Aji, vd., 2017; Joo ve Shim, 2010; Odabaş, 2014) sonucunda psikolojik güçlendirme ile örgütsel bağlılık arasında anlamlı ve pozitif ilişki olduğu belirlenmiştir. "Ayrıca yapılan bazı araştırmalarda, güçlendirmenin performans, üretkenlik, müşteri memnuniyeti, süreç iyileştirme ve ekip etkinliğini arttırdığını göstermiş̧tir” (Spreitzer, 2007, ss. 18-19). Yapılan araştırmalar psikolojik güçlendirmenin çalışanların örgütsel tutum ve davranışları üzerinde olumlu etkileri olduğunu göstermektedir. Bu nedenle psikolojik güçlendirmenin çalışanların örgütsel bağlılık düzeyi üzerine pozitif etkisi olması beklenmektedir.

AP7. Hizmetkar liderliğin örgütsel bağlılık üzerindeki etkisinde psikolojik güçlendirmenin aracılık etkisi var midır?

Asag-Gau ve Dierendonck (2011), yaptıkları çalışmada, hizmetkar liderliğin güçlendirme boyutunun örgütsel bağlılık üzerindeki etkisine psikolojik güçlendirmenin anlam boyutunun aracılık ettiğini belirlemişlerdir. Khajehpour, Baharlou, Montakhab Yeganeh ve Hashemi (2016), İran'da 232 çalışan üzerinde yaptıkları araştırmada hizmetkar liderliğin örgütsel bağlılık üzerindeki etkisinde 
psikolojik güçlendirmenin aracılık rolü olduğunu tespit etmişlerdir. Bu çalışmada hizmetkar liderliğin örgütsel bağlılık üzerindeki etkisinde psikolojik güçlendirmenin aracılık rolü olabileceği düşünülmektedir.

\section{Yöntem}

$\mathrm{Bu}$ araştırmada hizmetkar liderlik, örgütsel bağlllık ve psikolojik güçlendirme arasındaki ilişkiyi ortaya koyarak hizmetkar liderliğin örgütsel bağlllık üzerindeki etkisinde psikolojik güçlendirmenin aracılık rolü test edilmek istenmiştir. Araştırma kapsamında nicel araştırma yöntemlerinden nedensel araştırma tasarımı kullanılmıştır. Araştırmanın modeli, evren ve örneklemi, veri toplama araçları, verilerin toplanması ve analizi, araştırma etiği ile ilgili bilgiler aşağıda başlıklar halinde açiklanmıştır.

\section{Araştırmanın Modeli}

Araştırmanın modeli Şekil 1'de gösterilmiştir.

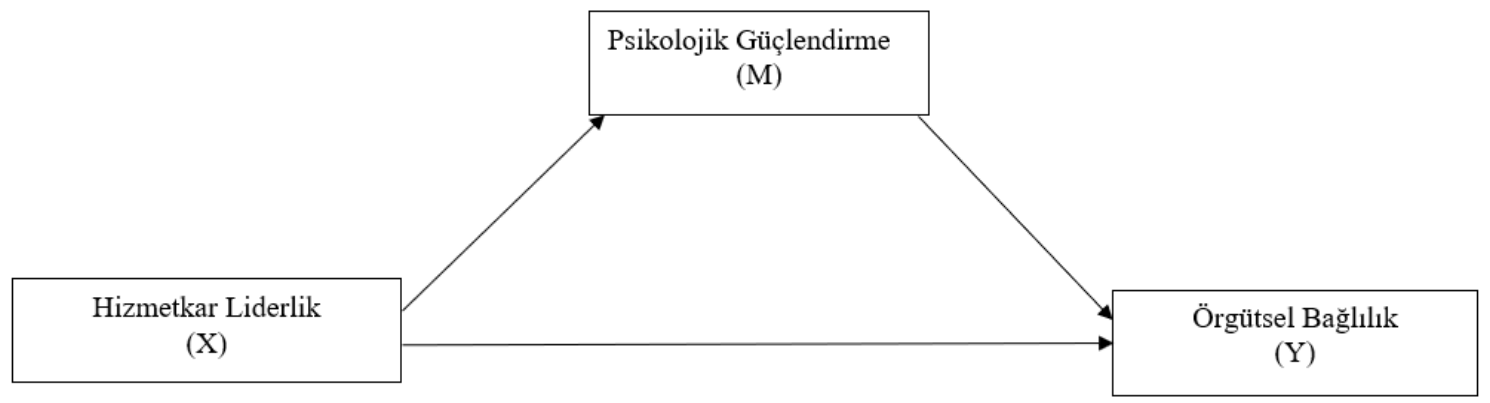

Şekil 1. Araştırmanın Modeli

\section{Evren ve Örneklem}

Araştırmanın evrenini, İstanbul ilinde faaliyet gösteren özel bir hastanede çalışan 385 sağlik personeli oluşturmaktadır. Örnekleme yöntemi olarak kolayda örnekleme yöntemi uygulanmıştır. Araştırmaya katılmayı kabul eden 234 kişiye anket formu dağıtılmış ve kendilerine uygun bir zamanda doldurmaları istenmiş ve daha sonra anket formları toplanmıştır. Eksik veya hatalı doldurulan 12 anket formu değerlendirme dışı bırakılmış ve toplam 222 katılımcının verileri değerlendirmeye alınmıştır.

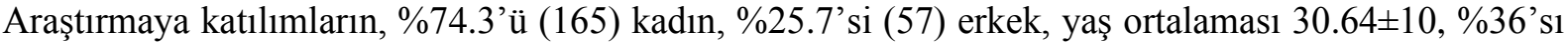
(80) lise mezunu, \%25.2'si (56) ön lisans mezunu, \%28.4'ü (63) lisans mezunu, \%10.4'ü (23) ise lisansüstü eğitim mezunudur.

\section{Veri Toplama Araçları}

Katılımcıların hizmetkar liderlik algısını ölçmek için Liden ve diğerleri (2013) tarafından geliştirilen ve Kılıç ve Aydın (2016), tarafından Türkçeye uyarlanan 7 madde ve tek boyuttan oluşan "Hizmetkar Liderlik Ölçeği”" kullanılmıştır. Liden ve diğerleri (2013), ölçeğin Cronbach Alfa güvenirlik katsayını 0.84 olarak bulmuş, Kılıç ve Aydın (2016), tarafından Cronbach Alfa değeri 0.87 olarak bulmuştur (Kılıç ve Aydın, 2016). Bu çalışmada ise Cronbach Alfa güvenirlik katsayısı 0.88 olarak bulmuştur. Cronbach Alfa güvenirlik katsayısı $0.80<\alpha<1.00$ arasındaki değerler yüksek düzeyde güvenilir olarak kabul edilmektedir (Yıldız ve Uzunsakal, 2018, s. 19). Bu sonuç Hizmetkar Liderlik Ölçeği’nin yüksek düzeyde güvenilir olduğunu göstermektedir.

Sağlık çalışanlarının örgütsel bağlılık düzeylerini ölçmek için Meyer, Allen ve Smith (1993) tarafından geliştirilen ve Türkçeye, Çevik Tekin (2019), tarafından uyarlanan 18 madde ve 3 boyuttan (duygusal bağl1lık, normatif bağl1lık, devam bağl1lı̆gl) oluşan "Örgütsel Bağl1lık Ölçeği" kullanılmıştır. Meyer, Allen ve Smith (1993), tarafindan ölçeğin Cronbach Alfa güvenirlik katsayı 
0.89 olarak bulunmuştur. Çevik Tekin (2019), ise Cronbach Alfa güvenirlik katsayıs1 0.90 olarak tespit etmiştir. Bu çalışmada Cronbach Alfa güvenirlik katsayısı 0.78 olarak bulmuştur. Cronbach Alfa güvenirlik katsayısı $0.60<\alpha<0.80$ arasındaki değerler oldukça güvenilir olarak kabul edilmektedir (Yıldız ve Uzunsakal, 2018, s. 19). Bu sonuç örgütsel bağl1lık ölçeğinin yüksek düzeyde güvenilir olduğunu göstermektedir.

Psikolojik güçlendirme düzeyini ölçmek için Spreitzer (1995), tarafindan geliştirilen ve Zhang ve Bartol'un (2010), çalışmasında kullanılan, Arslan, (2019) tarafından Türkçe'ye uyarlanan 12 madde ve 4 boyuttan oluşan "Psikolojik Güçlendirme Ölçeği" kullanılmıştır. Zhang ve Bartol (2010), tarafından ölçeğin Cronbach Alfa güvenirlik katsayısı 0.82 olarak bulunmuştur. Arslan (2019) tarafından ölçeğin Cronbach Alfa güvenirlik katsayısı 0.91 olarak saptanmıştır. Bu çalışmada ise Cronbach Alfa güvenirlik katsayını 0.89 olarak tespit edilmiştir. Cronbach Alfa güvenirlik katsayısı $0.80<\alpha<1.00$ arasındaki değerler yüksek düzeyde güvenilir olarak kabul edilmektedir (Yıldız ve Uzunsakal, 2018, s. 19). Bu sonuç psikolojik güçlendirme ölçeğinin yüksek düzeyde güvenilir olduğunu göstermektedir.

\section{Verilerin Toplanması ve Analizi}

Araştırma verilerinin kullanılmasında anket yöntemi kullanılmıştır. Toplanan verilerin analizi için IBM SPSS 25.0 programı kullanılmıştır. Değişkenler arasındaki ilişkinin incelenmesinde Pearson Korelasyon Analizi ve Basit Doğrusal Regresyon Analizi kullanılmıştır. Aracılık testinin analizinde Hayes, (2018) tarafindan geliştirilen Process Makro v3.4 uygulaması ile IBM SPSS programı kullanılmıştır. Analizde Bootstrap tekniği ile 5000 örneklem seçeneği ve model 4 tercih edilmiştir. Analizde Bootstrap tekniği ile yapılan aracılık etki analizinde \%95 güven aralığına (CI değerlerin sıfır (0) değerini kapsamadığı aralık) göre değerlendirme yapılmıştır.

\section{Araştırma Etiği}

Araştırmanın yapılmasında etik açıdan sakınca olmadığına dair Afyon Kocatepe Üniversitesi Sosyal ve Beşeri Bilimleri Bilimsel Araştırma ve Yayın Etiği Kurulunun 06.02.2020 tarih 2020/01 nolu etik kurul kararı alınmıştır. Araştırmanın yapıldığ 1 hastanenin yönetiminden çalışanlara anket uygulamak için yazılı izin alınmıştır. Araştırmaya katılmayı kabul eden katılımcıların sözlü onamları alınmıştır.

\section{Bulgular}

\section{Korelasyon Analizi Bulguları}

Hizmetkar liderlik ile örgütsel bağl1lık arasındaki ilişkiyi tespit etmek için Pearson Korelasyon Analizi uygulanmıştır. Pearson Korelasyon Analizine ait bulgular Tablo 1'de gösterilmiştir. Katılımcıların hizmetkar liderlik algısı puan ortalaması 3.70, örgütsel bağlılık puan ortalaması 3.04 psikolojik güçlendirme puan ortalaması 3.95 olarak tespit edilmiştir.

AP1 alt probleminin cevabını bulmak için yapılan korelasyon analizi sonucunda hizmetkar liderlik ile örgütsel bağlılık arasında pozitif yönlü ve orta düzeyde anlamlı bir ilişki olduğu $\operatorname{saptanmıştır~}(r=0.368, \mathrm{p}<0.01)$.

AP3 alt probleminin cevabını bulmak için yapılan korelasyon analizi sonucunda hizmetkar liderlik ile psikolojik güçlendirme arasında pozitif yönlü ve orta düzeyde anlamlı bir ilişki olduğu belirlenmiştir $(\mathrm{r}=0.360, \mathrm{p}<0.01)$.

AP5 alt probleminin cevabını bulmak için yapılan korelasyon analizi sonucunda örgütsel bağlılık ile psikolojik güçlendirme arasında pozitif yönlü ve düşük düzeyde anlamlı bir ilişki olduğu belirlenmiştir $(r=0.163, \mathrm{p}<0.05)$. 
Tablo 1

Korelasyon Analizi Bulgularl $(N=222)$

\begin{tabular}{llllll}
\hline Değişkenler & Ortalama & S.S & 1. & 2. & 3. \\
\hline 1. Hizmetkar liderlik & 3.70 & 0.85 & 1 & & \\
2. Örgütsel bağlllık & 3.04 & 0.54 & $0.368^{* * *}$ & 1 & \\
3. Psikolojik güçlendirme & 3.95 & 0.65 & $0.360^{* *}$ & $0.163^{*}$ & 1 \\
\hline
\end{tabular}

$*: \mathrm{p}<0.05, * *: \mathrm{p}<0.01$, S.S.: Standart Sapma

\section{Regresyon Analizi Bulguları}

Hizmetkar liderliğin örgütsel bağl1lık ve psikolojik güçlendirme üzerine etkisini ortaya koymak için Basit Doğrusal Regresyon Analizi yapılmıştır ve analiz bulguları Tablo 2'de gösterilmiştir. AP2 alt probleminin cevabını bulmak için yapılan regresyon analizi sonucunda, hizmetkar liderliğin örgütsel bağlılık üzerine pozitif yönde ve anlamlı bir etkisi olduğu saptanmıştır $(\beta=0.368, \mathrm{t}=5.868, \mathrm{p}$ $<0.01$ ). Örgütsel bağl1lık üzerinde meydana gelen değişikliğin \%13,5'i hizmetkar liderlik tarafindan açıklanmaktadır $\left(\mathrm{R}^{2}=0.135\right)$. AP4 alt probleminin cevabını bulmak için yapılan regresyon analizi sonucunda ise hizmetkar liderliğin psikolojik güçlendirme üzerinde pozitif yönde anlamlı bir etkisi olduğu belirlenmiştir $(\beta=0.360, t=5.722, p<0.01)$. Psikolojik güçlendirme üzerinde meydana gelen değişikliğin \%13'ü hizmetkar liderlik tarafından açıklanmaktadır $\left(\mathrm{R}^{2}=0.130\right)$.

Tablo 2

Regresyon Analizi Bulgulart

\begin{tabular}{|c|c|c|c|c|c|c|c|}
\hline \multicolumn{8}{|c|}{ Bağımsız değişken: Hizmetkar liderlik } \\
\hline $\begin{array}{l}\text { Bağımlı } \\
\text { değişkenler }\end{array}$ & $\mathrm{R}^{2}$ & $\begin{array}{c}\text { Düzeltilmiş } \\
\mathrm{R}^{2}\end{array}$ & B & Beta $(\beta)$ & $\mathrm{t}$ & $\mathrm{F}$ & $\mathrm{p}$ \\
\hline $\begin{array}{l}\text { Örgütsel } \\
\text { Bağlılık }\end{array}$ & 0.135 & 0.131 & 0.237 & 0.368 & 5.868 & 34.435 & 0.000 \\
\hline $\begin{array}{l}\text { Psikolojik } \\
\text { güçlendirme }\end{array}$ & 0.130 & 0.126 & 0.278 & 0.360 & 5.722 & 32.742 & 0.000 \\
\hline
\end{tabular}

Psikolojik güçlendirmenin örgütsel bağlılık üzerindeki etkisini test etmek için yapılan regresyon analizi bulguları Tablo 3'te gösterilmiştir. AP6 alt probleminin cevabını bulmak için yapılan regresyon analizi sonucuna göre psikolojik güçlendirmenin örgütsel bağl1l1k üzerinde pozitif yönde ve anlamlı bir etkisi olduğu belirlenmiştir $(\beta=0.163, t=2.451 \mathrm{p}<0.01)$. Örgütsel bağlllık üzerinde meydana gelen değişikliğin \%2.7'si psikolojik güçlendirme tarafından açıklanmaktadır $\left(\mathrm{R}^{2}=0.027\right)$.

Tablo 3

Psikolojik Güçlendirme ve Örgütsel Bağglllk Regresyon Analizi

Bağımsız değişken: Psikolojik Güçlendirme

\begin{tabular}{lccccccc}
\hline $\begin{array}{l}\text { Bağı̆mlı } \\
\text { değişken }\end{array}$ & $\mathrm{R}^{2}$ & $\begin{array}{c}\text { Düzeltilmiş } \\
\mathrm{R}^{2}\end{array}$ & $\mathrm{~B}$ & Beta $(\beta)$ & $\mathrm{t}$ & $\mathrm{F}$ & $\mathrm{p}$ \\
$\begin{array}{l}\text { Örgütsel } \\
\text { bağlılık }\end{array}$ & 0.027 & 0.022 & 0.136 & 0.163 & 2.451 & 6.009 & 0.000 \\
\hline
\end{tabular}




\section{Process Modülü ile Bootstrapp Regresyon Analizi Bulguları}

Hizmetkar liderliğin örgütsel bağlılık üzerindeki etkisinde psikolojik güçlendirmenin aracılık rolü olup olmadığını test etmek için Process modülü ile Bootstrap regresyon analizi yapılmıştır ve analiz bulguları Şekil 2 ve Tablo 4'te gösterilmiştir.

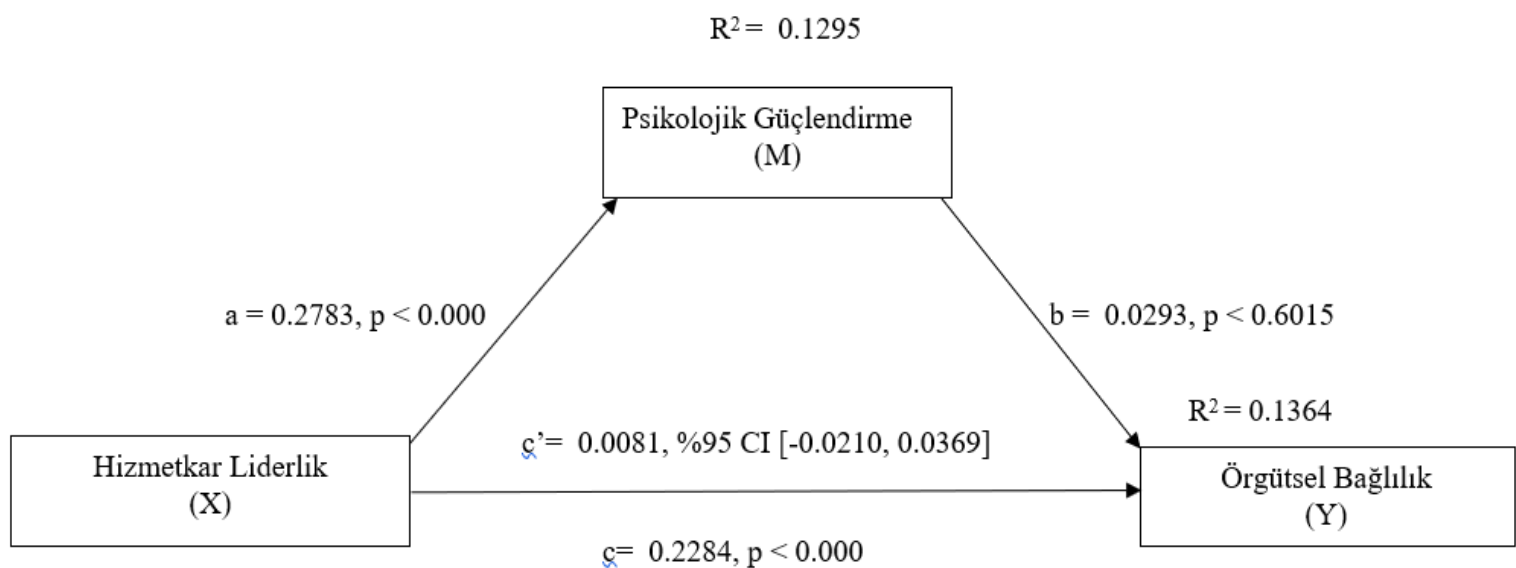

Şekil 2. Process Modülü ile Bootstrapp Regresyon Analizi Modelleme Bulguları

Yapılan analiz sonucunda, hizmetkar liderliğin örgütsel bağl1lı̆̆ anlamlı düzeyde ve olumlu yönde etkilediği saptanmıştır ( $\% 95$ CI [0.1571, 0.3160], $\mathrm{t}=5.8681, \mathrm{p}<0.01)$. Bu analiz sonucuna göre hizmetkar liderliğin örgütsel bağl1lık üzerindeki toplam etkisinin ise $\% 23$ olduğu tespit edilmiştir $(\mathrm{b}=$ 0.2365). Hizmetkar liderliğin örgütsel bağlllık üzerine doğrudan etkisinin \%22 olduğu ve bu etkinin anlamlı ve pozitif yönde olduğu saptanmıştır $(b=0.2284, \% 95$ CI $[0.1571,0.3160], t=5.2776, p$ $<0.01$ ). Hizmetkar liderliğin, örgütsel bağlllık üzerindeki etkisinde psikolojik güçlendirmenin aracılık rolü olup olmadığını test etmek ve AP7 alt probleminin cevabını bulmak için yapılan Bootstrap regresyon analizi sonucunda dolaylı etki bootstrap yönteminin \%95 güven aralı̆̆ının sıfırı (0) içermesi nedeni ile hizmetkar liderliğin, örgütsel bağll1ık üzerindeki etkisinde psikolojik güçlendirmenin anlamlı bir aracılık rolü olmadığı saptanmıştır $\left(c^{\prime}=0.081, \% 95\right.$ CI [-0.0210, 0.0369]).

Tablo 4

Process Modülü ile Bootstrapp Regresyon Analizi Bulguları (N=222)

\begin{tabular}{lclcccc}
\hline Değişkenler & Etki (b) & $\begin{array}{l}\text { Standart } \\
\text { hata }\end{array}$ & $\mathrm{t}$ & $\mathrm{p}$ & LLCI & ULCI \\
\hline $\begin{array}{l}\text { X' in, Y üzerine } \\
\text { toplam etkisi }\end{array}$ & 0.2365 & 0.0403 & 5.8681 & 0.000 & 0.1571 & 0.3160 \\
$\begin{array}{l}\text { X' in, Y üzerine } \\
\text { doğrudan etkisi }\end{array}$ & 0.2284 & 0.0433 & 5.2776 & 0.000 & 0.1571 & 0.3160 \\
& Etki (b) & $\begin{array}{l}\text { Bootstrap } \\
\text { Standart } \\
\text { hata }\end{array}$ & BootLLCI & BootULCI & & \\
$\begin{array}{l}\text { X' in, Y üzerine, } \\
\text { M'nin dolaylı etkisi }\end{array}$ & 0.081 & 0.0147 & -0.0210 & 0.0369 & & \\
\hline
\end{tabular}

$\mathrm{X}=$ Hizmetkar liderlik, $\mathrm{Y}=$ Örgütsel bağlılık, $\mathrm{M}=$ =Psikolojik güçlendirme

\section{Sonuç, Tartışma ve Öneriler}

Sağlık çalışanları üzerinde yapılan bu çalışmada, ilk olarak hizmetkar liderliğin örgütsel bağl1lık ve psikolojik güçlendirme üzerine etkisi incelenmiş daha sonra ise hizmetkar liderliğin örgütsel bağlılık üzerindeki etkisinde psikolojik güçlendirmenin aracılık etkisi olup olmadığ 1 analiz edilmiştir. 
Yapılan analiz sonucunda hizmetkar liderliğin örgütsel bağlılı̆g arttırıc1 etkisi olduğu saptanmıştır. Lapointe ve Vandenberghe (2018), müşteri hizmetleri departmanında görev yapan 181 çalışanın katılımı ile Kanada'da yaptıkları çalışmada hizmetkar liderlik ile örgütsel bağlılık arasında pozitif ilişki olduğunu tespit etmişlerdir. Harwiki (2016), Endonezya'da yaptığı çalışmada hizmetkar liderliğin örgütsel bağl1lık üzerine pozitif etkisi olduğunu tespit etmiştir. Miao ve diğerleri (2014) tarafinda Çin'de kamu çalışanları üzerinde yapılan çalışmada, hizmetkar liderliğin örgütsel bağl1lığın boyutları olan duygusal bağll1ık, normatif bağl1lık üzerine pozitif etkisi olduğunu ancak devam bağl1lı̆̆ üzerinde aynı etkinin olmadığını tespit etmişlerdir. Ramli ve Desa (2014), Malezya'da 143 çalışanın katılımı ile gerçekleştirdiği çalışmada hizmetkar liderlik ile örgütsel bağlılık arasında pozitif ilişki olduğunu belirlemiştir. Cerit (2010), tarafindan Düzce'de görev yapan 563 ilköğretim öğretmenleri üzerinde yaptığı çalışmada, hizmetkar liderlik ile örgütsel bağlılık arasında pozitif ilişki olduğunu saptamıştır. Bu araştırmanın sonuçları ile yapılan diğer araştırmaların sonuçlarının örtüştüğü görülmektedir.

$\mathrm{Bu}$ araştırmada hizmetkar liderliğin psikolojik güçlendirme üzerine olumlu etkisi olduğu görülmüştür. Zorlu ve diğerleri (2019), 309 otel çalışanı üzerinde yaptığı çalışmada hizmetkar liderliğin psikolojik güçlendirme üzerinde önemli etkisi olduğunu tespit etmişlerdir. Bolat ve diğerleri (2016) mobilya sektörü çalışanı 526 kişi üzerinde yaptıkları araştırmada hizmetkar liderlik ile psikolojik güçlendirme arasında pozitif ilişki olduğunu tespit etmişlerdir. Khajehpour ve diğerleri (2016), tarafından yapılan araştırmada hizmetkar liderliğin psikolojik güçlendirme üzerinde pozitif etkisi olduğunu tespit etmişlerdir. Yapılan diğer araştırmaların sonuçları ile bu araştırmanın sonuçları benzerlik göstermektedir.

$\mathrm{Bu}$ araştırmada psikolojik güçlendirmenin örgütsel bağlılı̆̆ arttırıcı etkisi olduğu saptanmıştır. Aji ve diğerleri (2017), tarafından 417 öğretim üyesi üzerinde yapılan çalışmada örgütsel bağl1lık ile psikolojik güçlendirme arasında pozitif ilişki olduğu tespit edilmiştir. Odabaş (2014), tarafından öğretmenler üzerinde yapılan çalışmada örgütsel bağlılık ile psikolojik güçlendirme arasında pozitif ilişki olduğu saptanmıştır. Joo ve Shim (2010), Kore'de kamu çalışanları üzerinde yaptıkları çalışmada örgütsel bağlılık ile psikolojik güçlendirme arasında pozitif ilişki olduğu belirlenmiştir. $\mathrm{Bu}$ araştırmanın sonuçları ile yapılan diğer araştırmaların sonuçlarının örtüştüğü görülmektedir.

$\mathrm{Bu}$ araştırmada hizmetkar liderliğin örgütsel bağl1lı üzerindeki etkisinde psikolojik güçlendirmenin aracılık etkisi olmadığı belirlenmiştir. Asag-Gau ve Dierendonck (2011), hizmetkar liderliğin örgütsel bağlılık üzerine etkisinde psikolojik güçlendirme ve zorlu iş koşullarının aracılık etkisini araştırmak için Hollanda'da bir hava yolu şirketinde çalışan 174 kişi üzerinde yaptıkları çalışmada, hizmetkar liderliğin güçlendirme boyutunun örgütsel bağlllık üzerindeki etkisine psikolojik güçlendirmenin anlam boyutunun aracılık ettiğini belirlemişlerdir. Khajehpour ve diğerleri (2016), İran'da bir endüstri şirketinde çalışan 232 katılımcı üzerinde yaptıkları araştırmada; hizmetkar liderliğin örgütsel bağl1lık üzerindeki etkisinde psikolojik güçlendirmenin aracılık rolü olduğunu tespit etmişlerdir. Farklı ülkelerde yapılan araştırmaların sonuçları ile bu araştırmada elde edilen sonuçların farklı olduğu görülmektedir. Araştırma sonuçlarının farklı çıkmasının nedeni, kültürler arası farklılıktan kaynaklanabileceği gibi örneklem grupları arasındaki farklılıktan da kaynaklanmış olabileceği düşünülmektedir. Ayrıca sonuçlar arasındaki farklılığın kaynağı, araştırmanın farklı sektör çalışanları üzerinde yapılmış olmasından da kaynaklanmış olabileceği düşünülmektedir.

$\mathrm{Bu}$ araştırmada hizmetkar liderliğin örgütsel bağlılı̆g 1 ve psikolojik güçlendirmeyi arttırdığı, psikolojik güçlendirmenin ise örgütsel bağlılığ1 arttırıcı etkisi olduğu tespit edilmiştir. Ayrıca hizmetkar liderliğin örgütsel bağlılık üzerindeki etkisinde psikolojik güçlendirmenin aracılık etkisi olmadığı saptanmıştır. Elde edilen bu sonuç hizmetkar liderliğin örgütsel bağlllık üzerinde doğrudan etkisi olduğunu bu etki üzerinde psikolojik güçlendirmenin aracılık rolü olmadığını göstermektedir.

Çalışanlarının örgütsel bağl1lık ve psikolojik güçlendirme düzeyini arttırmak isteyen sağlık yöneticileri hizmetkar liderlik davranışı sergileyerek bu amaca ulaşabilirler. 
Diğer ülkelerde yapılan araştırma sonuçları ile bu araştırmanın sonuçlarının farklı olduğu görülmüştür. Türkiye'de hizmetkar liderliğin örgütsel bağlılık üzerindeki etkisinde psikolojik güçlendirmenin aracılık etkisini araştıran başka bir çalışamaya rastlanmamıştır. Bu nedenle bu konuda sağlık sektöründe yeni araştırmaların yapılması uygun olacağı düşünülmektedir.

\section{Kaynaklar}

Aji, A. A., Hamid, J. A., Hassan, A. and Rasdi, R. M. (2017). Effect of organizational cultures on lecturers psychological empowerment and organizational commitment: structural equation modeling approach. IOSR Journal of Humanities and Social Science, 22(2), 71-82. doi:10.9790/0837-2203037182.

Arslan, F. (2019). Yiyecek-İ̧̧ecek çalışanlarında dönüşümcü liderlik ve yenilikçi iş davranışı ilişkisinde psikolojik güçlendirmenin aracı etkisi. Doktora tezi, Zonguldak Bülent Ecevit Üniversitesi Sosyal Bilimler Enstitüsü, Zonguldak.

Asag-Gau, L. and Van Dierendonck, D. (2011). The impact of servant leadership on organisational commitment among the highly talented: the role of challenging work conditions and psychological empowerment. European Journal of International Management, 5(5), 463-483. doi: 10.1504/EJIM.2011.042174.

Ateş, M. F. (2015). Hizmetkar liderlik ve örgütsel adaletin örgütsel özdeşleşmeye etkisinde örgütsel güvenin aracılık rolü. İşletme Araştırmaları Dergisi, 7(3), 75-95.

Barbuto, J. E. and D. W. Wheeler. 2006. Scale development and construct clarification of servant leadership. Group \& Organization Management, 31(3), 300-326. doi: $10.1177 / 1059601106287091$.

Baytok, A. ve Ergen, F. D. (2013). Hizmetkâr liderliğin örgütsel vatandaşlık davranışına etkisi: İstanbul ve Afyonkarahisar'daki beş yıldızlı otel işletmelerinde bir araştırma. Işsletme Araştırmaları Dergisi, 5(4), 105-132.

Biçer, C. (2020). Destructive leadership: "Boss from hell", How not to be one? Ahi Evran Üniversitesi Sosyal Bilimler Enstitüsü Dergisi, 6(1), 295-308. doi: 10.31592/aeusbed.623157.

Bolat, T., Bolat, O. İ. ve Yüksel, M. (2016). Hizmetkar liderlik ve psikolojik güçlendirme ilişkisi: Örgüt kültürünün düzenleyici etkisi. Ballkesir Üniversitesi Sosyal Bilimler Enstitüsü Dergisi, 19(36), 75-104.

Buchanan, B. (1974). Building organizational commitment: The socialization of managers in work organizations. Administrative Science Quarterly, 19(4), 533-546. doi: 10.2307/2391809.

Burns, J. M. (1979). Two excerpts from leadership. Educational Leadership, 36(6), 380-383.

Cerit, Y. (2010). The effects of servant leadership on teachers' organizational commitment in primary schools in Turkey. International Journal of Leadership in Education, 13(3), 301-317. doi: 10.1080/13603124.2010.496933.

Conger, J. A. and Kanungo, R. N. (1988). The empowerment process: Integrating theory and practice. Academy of Management Review, 13(3), 471-482. doi: 10.2307/258093.

Çavuşoğlu, F. ve Güler, M. E. (2017). Psikolojik güçlendirme ile örgütsel vatandaşlık davranışının ilişkisi ve demografik değişkenlere göre farkl11ıkları: İzmir şehir merkezindeki konaklama işletmelerinde bir araştırma. Seyahat ve Otel İşletmeciliği Dergisi, 14(2), 47-64. doi: $10.24010 /$ soid. 334336 . 
Çelik, O. T. ve Üstüner, M. (2020). Ortaokul öğretmenlerinin örgütsel politika algıları ile örgütsel bağl1lıkları ve örgütsel vatandaşlık davranışları arasındaki ilişki. Hacettepe Üniversitesi Ĕgitim Fakültesi Dergisi, 35(1), 120-135. doi: 10.16986/HUJE.2018044109.

Çevik, Tekin, İ. (2019). Psikolojik güçlendirmenin yenilikçi iş davranışına etkisinde örgütsel bağlılı̆̆ın aracılık rolü: Türkiye otomotiv üreticileri araştırması. Doktora Tezi, Selçuk Üniversitesi Sosyal Bilimler Enstitüsü, Konya.

Dal, L. (2014). Hizmetkar liderlik ile lider-üye etkileşimi arasındaki ilişki: bir devlet üniversitesinde araştırma. Yüksek Lisans Tezi, Eskişehir Osmangazi Üniversitesi Sosyal Bilimler Enstitüsü, Eskişehir.

Duygulu, S. ve Abaan, S. (2007). Örgütsel bağl1lık: Çalışanların kurumda kalma ya da kurumdan ayrılma kararının bir belirleyicisi. Hacettepe Üniversitesi Hemşirelik Fakültesi Dergisi, 14(2), 61-73.

Ehrhart, M. G. (2004). Leadership and procedural justice climate as antecedents of unit-level organizational citizenship behavior. Personnel Psychology, 57, 61-94. doi: 10.1111/j.17446570.2004.tb02484.x.

Erdağı, K. (2018). Işs doyumu ile örgütsel bağlllık arasındaki ilişki: hizmet sektöründe bir uygulama. Yüksek Lisans Tezi, İstanbul Gelişim Üniversitesi Sosyal Bilimler Enstitüsü, İstanbul.

Erdoğdu, F. B. ve Sökmen, A. (2019). Örgütsel bağlllık ile iş tatmini ve işten ayrılma niyeti ilişkisinde örgütsel vatandaşlık davranışının aracılık rolü. Journal of Tourism and Gastronomy Studies, 7 (1), 244-264. doi: 10.21325/jotags.2019.362.

Eren, E. (2015). Örgütsel davranışv ve yönetim psikolojisi. İstanbul: Beta Basım.

Greenleaf, R. K. (1970). The servant as leader. New York: Paulist Press.

Greenleaf, R. K. (2002). Servant leadership: A journey into the nature of legitimate power and greatness. New Jersey: Paulist Press.

Hamilton, F. (2008). Servant leadership. A. Marturano and J. Gosling (Ed.), Leadership the key concepts in (pp. 146-150). London: Routledge.

Harwiki, W. (2016). The impact of servant leadership on organization culture, organizational commitment, organizational citizenship behaviour (OCB) and employee performance in women cooperatives. Procedia-Social and Behavioral Sciences, 219(1), 283-290. doi: https://doi.org/10.1016/j.sbspro.2016.04.032.

Hayes, Andrew F. (2018). Introduction to mediation, moderation, and conditional process analysis: A regression-based approach (Second Edition). New York: The Guilford Press.

İhtiyaroğlu, N. (2017). Yapısal ve psikolojik güçlendirmenin öğretmen motivasyonu üzerindeki etkisi. Kırlkkale Üniversitesi Sosyal Bilimler Dergisi, 7(2), 361-378.

Joo, B. K. and Shim, J. H. (2010). Psychological empowerment and organizational commitment: the moderating effect of organizational learning culture. Human Resource Development International, 13(4), 425-441. 
Kanbur, E. (2018). Havacılık sektöründe psikolojik güçlendirme, iş performansı ve işten ayrılma niyeti arasındaki ilişkilerin incelenmesi. Uluslararası Yönetim İktisat ve İşletme Dergisi, 14(1), 147162. doi: 10.17130/ijmeb.2018137578.

Karakuş, K. (2019). Okul yöneticilerinin psikolojik güçlendirme davranışları ile ögretmenlerin iş doyumu arasındaki ilişki. Yüksek Lisans Tezi, Pamukkale Üniversitesi Eğitim Bilimleri Enstitüsü, Denizli.

Kaya, Ç. and Altınkurt, Y. (2018). Role of psychological and structural empowerment in the relationship between teachers' psychological capital and their levels of burnout. Education and Science, 43(193), 63-78. doi: 10.15390/EB.2018.6961.

Khajepour, N., Baharlou, M., Montakhab Yeganeh, M. and Hashemi, S. E. (2016). The mediating role of psychological empowerment and organizational justice in the relationship of servant leadership with job satisfaction, organizational citizenship behavior and organizational commitment. International Journal of Behavioral Sciences, 10(2), 99-105.

Kılıç, K. C. ve Aydın, Y. (2016). Hizmetkâr liderlik ölçeğinin Türkçe uyarlaması: Güvenirlik ve geçerlik çalışması. KMÜ Sosyal ve Ekonomik Araştırmalar Dergisi, 18(30), 106-113.

Kılınç, S. ve Yener, S. (2019). İşkolikliğin örgütsel bağlılık ve performans arasındaki ilişkide aracı rolü. Adıyaman Üniversitesi Sosyal Bilimler Enstitüsü Dergisi, 12(33), 678-713. doi:10.14520/adyusbd.417837.

Koçel, T. (2011). Işsletme yöneticiliği. İstanbul: Beta Basım.

Lapointe, E. and Vandenberghe, C. (2018). Examination of the relationships between servant leadership, organizational commitment, and voice and antisocial behaviors. Journal of Business Ethics, 148(1), 99-115. doi: 10.1007\%2Fs10551-015-3002-9.

Larry, C. and Spears, C. L. (2010). Servant leadership and Robert K. Greenleaf's legacy. Dierendonck, D. V. and K, Patterson, K. (Ed.), Servant leadership: Developments in theory and research in (pp. 11-24). New York: Palgrave Macmillan.

Lowman, R. L. (1993). Counseling and psychotherapy of work dysfunctions. Washington: American Psychological Association.

Melchar, D. E. and Bosco, S. M. (2010). Achieving high organization performance through servant leadership. The Journal of Business Inquiry, 9(1), 74-88.

Meyer, J. P. and Allen, N. J. (1997). Commitment in theworkplace: Theory, research, andapplication. London: Sage Paplications.

Meyer, J. P., Allen, N. J. and Smith, C. A. (1993). Commitment to organizations and occupations: Extension and test of a three-component conceptualization. Journal of Applied Psychology, 78(4), 538-551. doi: 10.1037/0021-9010.78.4.538.

Miao, Q., Newman, A., Schwarz, G. and Xu, L. (2014). Servant leadership, trust, and the organizational commitment of public sector employees in China. Public Administration, 92(3), 727-743. doi: 10.1111/padm.12091.

Mowday, R. T., Steers, R. and Porter, L. W. (1979). The measurement of organizational commitment. Journal of Vocational Behavior, 14(2), 224-247. doi:10.1016/0001-8791(79)90072-1. 
Odabaş, İ. (2014). Yapısal güçlendirme ile örgütsel bağlllık arasındaki ilişkide psikolojik güçlendirmenin ara değişken rolü: öğretmenler üzerinde bir çalışma. Yüksek Lisans Tezi, İstanbul Kültür Üniversitesi Sosyal Bilimler Enstitüsü, İstanbul.

Özata, M. ve Topçu, T. (2018). Sağllk personelinde motivasyon ile örgütsel bağl1lık arasındaki ilişkinin araştırılması: Bandırma Devlet Hastanesi örneği. Ahi Evran Üniversitesi Sağllk Yüksek Okulu Sağlık Bilimleri Dergisi, 2(3), 17-24.

Özdemir, H. Ö. (2019). Konaklama işletmelerinde çalışan personelin örgütsel bağl1lıklarının sosyodemografik faktörler açısından incelenmesi. Ahi Evran Üniversitesi Sosyal Bilimler Enstitüsü Dergisi, 5(2), 237-250. doi: 10.31592/aeusbed.580740.

Page, D. and Wong, T. P. (2000). A conceptual framework for measuring servant leadership. S. Adjibolosoo (Ed.), Shaping the course of history and development in (pp. 69-110). Lanham, MD: University Press of America.

Ramli, A. and Desa, N. M. (2014). The relationship between servant leadership and organizational commitment: The Malaysian perspectives. International Journal of Management and Sustainability, 3(2), 111-123.

Reichers, A. E. (1985). A reviewand reconceptualization of organizational commitment. Academy of Management Review, 10(3), 465-476. doi: 10.2307/258128.

Spears, L. C. (2004). Practicing servant leadership. Leader to Leader, 34, 7-11. DOI: 10.1002/lt1.94.

Spreitzer, G. (2007). Taking stok: A review of more than twenty years of research on empowerment at work. Handbook of Organizational Behaviour, 1, 54-72. doi: 10.4135/9781849200448.n4.

Spreitzer, G.M. and Doneson, D. (2008). Musings on the past and future of employee empowerment. T. Cummings (Ed.), Handbook of organizational development in (pp. 5-10). Thousand Oaks, CA: Sage.

Stogdill, R. M. (1950). Leadership membership and organization. Psychological Bulletin, 47(1), 1-14. doi: $10.1037 / \mathrm{h} 0053857$.

Stone, A. G., Russell, R. F. and K. Patterson. (2004). Transformational versus servant leadership: A difference in leader focus. Leadership \& Organization Development Journal, 24(3/4), 349361. doi: $10.1108 / 01437730410538671$.

Tanrı̈ğen, Z. M. ve Çoban, O. (2019). Okul müdürlerinin hizmetkâr liderlik davranışları ile öğretmenlerin iş doyumu arasındaki ilişkiler. Electronic Turkish Studies, 14(4), 2705-2723. doi: 10.29228/TurkishStudies.24802.

Thomas, K. W. and Velthouse, B. A. (1990). Cognitive elements of empowerment. Academy of Management Review, 15(4), 666-681. doi: 10.2307/258687.

Torun, Y. (2016). Personel güçlendirme vee işten ayrllma niyeti iliş̧isinde örgütsel sinizmin aracllı rolü: Örgütsel sinizm ölçeği geliştirmeye yönelik bir araştırma. Doktora Tezi, Marmara Üniversitesi Sosyal Bilimler Enstitüsü, İstanbul.

Tufail, M., Zia, Y. A., Khan, S. and Irfan, M. (2012). Glance at organizational commitment, antecedents and consequences (1960-2005). Journal of Managerial Sciences, 6(1), 73-91. 
Turhan, M., Erol, Y. C., Demirkol, M. ve Özdemir, T. Y. (2018). Örgütsel bağl1l1k, iş doyumu ve iş stresi arasındaki ilişki. Electronic Turkish Studies, 13(27), 1491-1507. doi: 10.7827/TurkishStudies.14328.

Wiener, Y. (1982). Commitment in organizations. a normativeview. Academy of Management Review, 7(3), 418-428. doi: 10.2307/257334.

Uzunsakal, E. ve Yıldız, D. (2018). Alan araştırmalarında güvenilirlik testlerinin karşılaştırılması ve tarımsal veriler üzerine bir uygulama. Uygulamalı Sosyal Bilimler Dergisi, 2(1), 14-28.

Yorulmaz, A. ve Çelik, S. (2016). İlkokul öğretmenlerinin örgütsel bağlllık, örgütsel sinizm ve örgütsel vatandaşlık davranışları arasındaki ilişki. Kalem Ĕ̈itim ve İnsan Bilimleri Dergisi, 6(1), 161-193. doi: 10.23863/kalem.2017.60.

Zorlu, Ö., Avan, A. and Baytok, A. (2019). The effect of servant leadership on psychological empowerment and organizational identification. Journal of Business Research-Turk, 11(1), 293-309. doi: 10.20491/isarder.2019.600. 


\section{Extended Abstract}

\section{Introduction}

Research on leadership has been continuing since the early 1900s. As a result of these researches, many types of leadership (charismatic, transformational, transactional, paternalist etc.) have been defined according to the behaviors of the leaders. Greenleaf (1970) proposed a new leadership style called Servant Leadership. However, the interest of researchers on servant leadership was formed as of 1990 and it was observed that the number of researches on servant leadership increased in this period. Today, studies on servant leadership are increasing. In general, the main subject of these researches was to determine how the managers' servant leadership behaviors affect the behavior and attitudes of the employees. In researches, servant leadership and organizational commitment (Cerit, 2010; Harwiki, 2016; Lapointe and Vandenberghe, 2018; Miao et al., 2014; Ramli and Desa, 2014), psychological empowerment (Zorlu et al., 2019; Bolat et al., 2016), organizational justice, organizational identification (Ateş, 2015), job satisfaction (Tanrı̈ğen and Çoban, 2019), leader-member exchange (Dal, 2014), organizational citizenship (Baytok and Ergen, 2013) relationships were examined. This research was conducted to examine the intermediary role of psychological empowerment on the impact of servant leadership on organizational commitment. In the literature research, it was seen that there are very few studies on this subject. Also not found a study examining this issue in Turkey. This research is intended to contribute to fill this gap in the literature.

\section{Method}

The sample of the study consists of 222 healthcare professionals working in a private hospital in Istanbul. In the research a questionnaire was used as the main data collection tool. IBM SPSS 25.0 program was used to analyze the data. Pearson Correlation Analysis and Simple Linear Regression Analysis were used to examine the relationship between variables. In the analysis of the moderator effect, the Process Macro v3.4 application developed by Hayes (2018) and IBM SPSS program were used. The "Servant Leadership Scale" consisting of 7 items and a single dimension developed by Liden et al. (2013) and adapted to Turkish by Kiliç and Aydın (2016) was used to measure the perceptions of the Servants Leadership. The "Organizational Commitment Scale" consisting of 18 items and 3 dimensions (affective commitment, normative commitment, continuance commitment) developed by Meyer, Allen and Smith (1993) and adapted to Turkish by Çevik Tekin (2019) was used to measure the level of organizational commitment of healthcare professionals. The "Psychological Empowerment Scale", which was developed by Spreitzer (1995) and used in the study of Zhang and Bartol (2010) and was adapted to Turkish by Arslan (2019), was used to measure the level of psychological empowerment of the participants.

\section{Result}

The participants are $74.3 \%$ (165) female, $25.7 \%$ (57) male and the average age is $30.64 \pm 10.43$. Participants' perception of servant leadership score was determined as $3.70 \pm$ 0.87 , average of organizational commitment score was $3.04 \pm 0.54$, and psychological empowerment score average was $3.95 \pm 0.65$. The analysis demonstrated that servant leadership has a positive effect on psychological empowerment and organizational commitment. Also, according to the regression analysis result, psychological empowerment has a positive and significant effect on organizational commitment. However, it was observed 
that psychological empowerment does not play intermediary role on the impact of servant leadership on organizational commitment.

\section{Discussion and Conlusion}

In this study, it was determined that that psychological empowerment does not play intermediary role on the impact of servant leadership on organizational commitment. AsagGau and Dierendonck (2011), conducted a research on 174 people working in an airline company in the Netherlands. They determined that the meaning dimension of psychological empowerment intermediary role of empowerment dimension of servant leadership on organizational commitment. Khajehpour et al. (2016), in their research on 232 participants working in an industrial company in Iran; They found that psychological empowerment has intermediary role in the impact of servant leadership on organizational commitment. The results of the research conducted in other countries and the results of this research were found different. It is thought that the reason for the different results of the research may be due to the difference between cultures as well as the difference between the sample groups. It is also thought that the source of the difference between the results may have resulted from the fact that the research was conducted on different sector employees.

There is no other research examining the intermediary role of psychological empowerment in the impact of servant leadership on organizational commitment in Turkey. Therefore, it is considered that it will be appropriate to conduct new researches in the health sector on this subject. 